\title{
Research on Foreign Travelers Credit Management Model on the Basis of China's Transit Visa-Free Policy
}

\author{
Qi Kai ${ }^{1,2}$

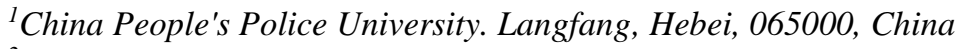 \\ ${ }^{2}$ Minzu University of China.Haidian, Beijing, 100089, China \\ Corresponding author's e-mail:420070368@qq.com
}

\begin{abstract}
China's transit visa exemption policy has established an open and inclusive image of great power, which has played a function to promote both international exchanges and personnel exchanges and to enhance the status of relevant port cities as an international transportation hub. On the basis of exploring the China's regularities of entry and exit, this article reviews the current situation and regularities of the management of foreigners in transit, analyzes the phased characteristics and implementation effects of the transit visa exemption policy in the new era, and makes proposes that the establishment of a more scientific and reasonable management model for foreign travelers based on the new pattern of opening up in the new era. This paper is going to provide suggestions for the development and improvement of immigration management with Chinese characteristics in the new era.
\end{abstract}

Keywords: transit visa-free, credit management, immigration policy

\section{INTRODUCTION}

With the continuous deepening of reform and opening up, China's exchanges with the world have become increasingly frequent. Under this context, international urban clusters within China have continued to rise, and the integration of transportation networks has promoted global interoperability. The international flow of travelers has continued to increase. Based on this new situation, China has formulated a series of immigration management service policies and has taken measures to promote and regulate the reasonable flow of foreigners within China, including the introduction of a visa exemption policy for foreigners in transit. The policies have met the needs of facilitating the tourists, and have also promoted cities' the economic development and influence covered by policies. And all in all, they have improved China's economic strength and international influence.

\section{GENERAL SITUATION OF VISA-FREE TRANSIT POLICY AND ITS DEVELOPMENT IN CHINA}

Countries around the world usually require foreigners to apply for visas in advance, i.e. national visa agencies overseas will conduct preliminary checks on the identity of the applicants and their purposes of entry before their entrance, and will not issue visas to those who may endanger their national security. Personnel need to wait for the completion of visa and post it on the passport visa page for use. With the deepening of exchanges among countries and the needs of their own development, many countries have gradually implemented visa-free facilitation measures for certain foreigners. For example, the signing of mutual visa exemption agreements between governments of various countries; exemption for foreigners holding residence certificates in their own countries Visa etc.

The transit visa exemption policy is one of the contents of the visa exemption system implemented by countries around the world. It means that foreigners do not need to apply for a transit country visa when transiting from one country to a third country in accordance with the laws or relevant regulations of the transit country. Article 22 of the Exit and Entry Administration Law of the People's Republic of China stipulates that "Foreigners who have one of the followings can be exempted from applying for a visa: holding a connecting ticket on an aircraft, ship, or train in an international voyage from China to a third country areas, staying in China for no more than 24 hours without leaving the port, or staying in a specific area approved by the State Council for no more than the 
prescribed time limit; other circumstances under which visa exemption is provided by the State Council." Foreign nationals who apply for transit visa exemption passengers within the scope of the applicable transit visa exemption policy, only need to provide international travel documents that can prove their nationality, a joint ticket with a confirmed date and seat within the time limit of the visa exemption, and a connecting ticket to a third country or region from the permitted exit port and relevant certificates can be used for short-term entry. Foreigners who meet the requirements should apply to the airline that carried them to China, and the airline that carried them or their entry and exit can declare to the immigration inspection authority.

The transit visa exemption policy has promoted the continuous increase in the number of foreigners who come to China for tourism, visits, and investments. With the opening of China's door to the outside world, more and more foreigners choose to transit through China. Since the promulgation of the Exit and Entry Administration Law of the People's Republic of China, China's transit visa exemption policy has evolved from the 24-hour transit visa exemption at the beginning of the implementation to the 72-hour transit visa exemption implemented at 15 open ports, and then to the current implementation of some ports in China. The 144-hour transit visa-free policy has attracted more and more foreigners to come for trade, tourism and exchange visits, which has greatly promoted the economic development and influence of relevant cities in China. For example, the Beijing-Tianjin-Hebei region has implemented a 144-hour visa-free transit policy for foreigners since December 28, 2017. It covers Beijing Capital International Airport, West Railway Station, Tianjin Binhai International Airport, Tianjin International Cruise Homeport, Hebei Shijiazhuang International Airport, and Qinhuangdao Seaport. For foreigners in 53 countries including Austria who hold a valid international travel document and a joint ticket to a third country (region) with a confirmed date and seat within 144 hours, the transit visa-free policy will be implemented. Transit foreigners can choose to enter or exit the country from any of the above 6 ports and stay visa-free for 144 hours in the administrative regions of Beijing, Tianjin, and Hebei Province[1].

According to statistics from the National Immigration Administration, from January 2013 to September 2019, 452,000 foreigners have entered China through this policy; as of June 2020, 18 provinces (autonomous regions and municipalities included), 23 cities, and 30 ports in China have implemented a 72hour, or 144-hour visa exemption policy for people from 53 countries. Among them, three ports in Changsha, Guilin, and Harbin have implemented a 72-hour visafree policy for foreigners in transit. 27 ports in 20 cities including Beijing, Tianjin, Shijiazhuang, Qinhuangdao, Shanghai, Hangzhou, Nanjing, Shenyang, Dalian,
Qingdao, Chengdu, Xiamen, Kunming, Wuhan, Guangzhou, Shenzhen, Jieyang, Chongqing, Xi'an, and Ningbo have implemented a 144-hour visa-free policy for foreigners to transit through the border, and realize regional and port linkages in the Beijing-Tianjin-Hebei, Yangtze River Delta and other regions to serve China's Open-up strategy and maintain international customs clearance order.

The transit visa exemption policy presents three characteristics in the implementation and development of China. One is the continuous expansion of the implementation area, gradually expanding from a single port city to a regional urban agglomeration; the second is the extension of the visa exemption period, and the time is changed from the initial one. The 24 hours have been extended to the current longest 144 hours, so that foreigners in transit can have sufficient time to engage in short-term activities such as tourism, business exhibitions, visiting relatives and friends; the third is the types of transit visa-free ports have increased, from the original single airport. To railway ports and sea ports, it is convenient for international passengers to choose more convenient transportation means for transit, and promote the reasonable matching of multiple transportation resources and rational operation.

From the perspective of implementation effects, the transit visa-free policy has promoted international cultural exchanges and dissemination of China's economy, promoted the development of the inbound tourism market, and improved the regional economic strength and international influence of port city groups. As the door of China's opening up to the outside world has opened wider and wider, China has also welcomed more foreign friends to offer suggestions and contributions to its development in a more open manner. China's transit visa-free policy has established an open and inclusive large country image and promoted international exchanges and personnel exchanges, which have also enhanced the status of relevant port cities as international transportation hubs, and played a stimulating role in the economic development of surrounding urban agglomerations.

\section{CHALLENGES IN THE MANAGEMENT OF TRANSIT VISA-FREE FOREIGN PASSENGERS}

As China has signed visa-free agreements with more and more countries in the world, the number of passengers who meet the visa-free policy continues to increase. Foreigners who apply the transit visa-free policy are international transit passengers and can choose their transit destination in other countries. For commuting passengers, an efficient and convenient transit experience is an important factor in choosing a transit place. The transit visa exemption scope includes dozens of countries, and each country has different laws 
and cultures. On one hand, it is necessary to exempt foreign countries in transit. In human management, the mandatory management is weakened, and management is self-directed. On the other hand, it is necessary to ensure national security and social stability. During the implementation of the policy, some foreigners in transit do not comply with relevant laws and regulations and social ethics which have affected the normal order of entry and exit.

\subsection{Facilitation Requirements for Transit Visa Exemption Pose A Challenge to the Management Model}

While the transit visa exemption policy brings development dividends, it also poses a challenge to the effective management of foreign passengers in China. In practice, the facilitation requirements for transit visa exemption will simplify the procedures for inspection, review, and procedures at the port within a short time. Fully verifying the visa-free qualifications of transit passengers, subject to international information exchange conditions and many restrictions on the onsite duty, it is difficult for them to have background information, family affiliate information, real purpose of coming to China, itinerary arrangements, accommodation, etc. within a limited time. The information is fully verified, and the follow-up itinerary cannot be followed up immediately[2].

\subsection{The Attractiveness and Economic Benefits of the Transit Visa-free Policy Are Not Fully Utilized}

The purpose of the transit visa exemption policy is to facilitate the movement of international tourists and promote the economic development of transit cities. Since the implementation of China's transit visa exemption system, the number of foreign tourists applying for this system has been lower than expected. As results of the relatively short transit time and visa exemption, other more famous the target country, the not prominent status of the port city hub, the entry and exit port area restrictions, the imperfect supporting services, the low policy awareness, etc, many foreign travelers who may meet the visa exemption conditions do not choose to stay in China during the transit period. The attractiveness and economic benefits of the city are not fully utilized. Compared with the transit visa-free cities in neighboring countries and regions, it lacks a clear competitive advantage.

\section{THE ESTABLISHMENT OF A CREDIT MANAGEMENT MODEL FOR TRANSIT VISA-FREE FOREIGN PASSENGERS}

Credit management is a management behavior that uses credit as a lever. Its management method is soft, timely, practical, and efficient. The credit management of visa-free foreigners in transit is based on the entry risk assessment, credit evaluation as the basis, hierarchical management as the means, and multi-party co-management as the guarantee, and closed-loop management of the entry, stay and exit process of transit visa-free foreigners. The management information also serves as the basis for applying the transit visa-free policy in my country in the future[3].

\subsection{Pre-risk Assessment for Transit Visa-free Personnel}

Before boarding, passengers in transit use the transit credit application platform based on big data and bioinformatics to register their credit information online, upload passports, signatures, and photos of the connecting ticket for automated screening, and then answer virtual entry and exit via web cameras. For questions raised by personnel, the system uses automatic lie detection technology to identify whether passengers are in good faith and abiding by the law, and informs the laws and regulations during transit in China in advance, so as to realize the rapid entry of trusted transit visa-free passengers upon arrival, and at the same time identify, detect and prevent high entry of risk groups[4] .

\subsection{Entry Credit Evaluation of Visa-free Transit Personnel}

The entry-exit border inspection agency establishes a credit file for the first transit through the information sharing and exchanges between visa-free countries, the passenger data interaction of international airlines, and the personal information declared by transit passengers in advance, planned itinerary, etc. Comparing the previous transit records, analyzing and judging the status of the transit visa-free foreigners' compliance with laws, regulations and relevant international conventions, and judging whether the parties concerned can enjoy the transit visa-free policy, the entry-exit border inspection agency discovers and gives feedback in advance based on credit information. Avoiding unnecessary economic losses caused by airlines and passengers unable to enter the country due to inconsistent qualifications or other reasons, and improve issuance efficiency and control accuracy.

\subsection{Hierarchical Management of Transit Visa- free Personnel During Their Stay}

During the entry and stay period of visa-free transit persons, the administrative department implements graded services and differentiated management based on the credit rating assessed, and adopts measures such as facilitating transit, providing guarantees, restricting convenience, and not allowing entry into the country based on credit ratings. Well behaved people who have contributed to China's education, science, culture, health, etc. provide the most convenient services; on the 
other hand, having established a daily inspection system for cross-border personnel who may have credit risks, and compare and collide information from entry to exit behavior trajectory to grasp in time. Itinerary dynamics and violations of laws and regulations, for foreigners who have overstayed, illegally employed, exceeded the scope of visa exemption, and unregistered accommodation, the management department will immediately receive an alarm and make corresponding actions.

\subsection{Form the Credit File of the Transit Visa- free Personnel}

By recording the itinerary, entry route, scope of stay, exit time, and whether there is any negative record during the period of stay in China, as the main basis for considering whether the convenience policy can be enjoyed again, it will violate the provisions of the transit visa exemption policy. Foreigners' behaviors are recorded in credit files, forming negative integrity records, and those who have illegal entry and exit activities, such as declaring false personal information, holding fake documents, and illegal residence in China, is going to be clustered in the "blacklist". Government of China will make the decision whether to allow them to transit through in the future as a qualification certificate.

\subsection{Multi-party Joint Supervision of Transit Visa-free Personnel}

The smooth implementation of the transit visa exemption policy and the immigration management, civil aviation, transportation, health, tourism and other units, each department should realize in-depth data sharing based on the credit evaluation of transit foreigners, strengthen communication and cooperation, and apply for transit visa exemption from foreigners. From the beginning of the formalities to its arrival at the port, and its activities within a limited time restrain and within a limited range realize linkage supervision. For example, when a foreigner declares entry from a country with a highly infectious disease, the system will automatically connect and share with the corresponding inspection, quarantine and health departments and generate an early warning, conduct key epidemic prevention inspections when entering the country, and provide immediate supervision and feedback on the movement track and health status during the stay.

The credit management of visa-free transit for foreign passengers demonstrates my country's peopleoriented attitude as a major country, promotes my country's cultural dissemination and economic development in transit cities, enhances my country's soft power in international exchanges, and can warn and punish transit violations, and is also a legal and trustworthy International passenger traffic brings great convenience.

\section{CONCLUSION}

Enterprise government must introduce competition mechanism and apply innovative strategies under the market-oriented concept. Currently, China is in a critical period of changing government functions. The idea of an enterprise government will undoubtedly provide a new way of thinking for the reform of our government. This article discusses the transformation of government functions based on the actual situation in China. Then structural policies is proposed, which provides feasible ideas and reference solutions for the future government reform. Not only this has the theoretical significance, but also has certain practice value.

\section{ACKNOWLEDGMENT}

This work was supported by the Project of China People's Police University: Foreign travelers based on my country's transit visa-free policy Research on Credit Management Model (No. ZQN2018026)

Research and Practice Project of Higher Education Reform in Hebei Province: Research and Practice on the Construction of Immigration Management Professional Talent Training System"(2018GJJG434)

\section{REFERENCES}

[1] National Immigration Administration. (2019) Reading! The 144-hour transit visa-free policy for foreigners was extended to 27 ports https://www.nia.gov.cn/n741440/n741577/c11744.

[2] Jiang tao.(2015)Analysis on 72-hour transit visa-free border inspection for foreigners. Journal of armed police academy,31(01):20-23.

[3] Cheng Yonghui.(2014) New Exploration on Marxist Concept of Equality. Hunan Provincial Party School of CPC.

[4] Qi Kai, Wang Hao. (2020) China's Exit and Entry Credit and its Management Model. Journal of China Criminal Police Academy,2020(02):88-95.

[5] Wang Haiqin.(2011)Research on the Innovative Mode of Foreign Police Management in Guangzhou. Lanzhou University.

[6] MAO Jian. (2014) Study on the Management Mode of Foreigners in China. Fudan University. 